\title{
TSH-Secreting Pituitary Adenoma Identified in Pregnancy: Management of an Unusual Case
}

Case History:

35 year old Columbian lady. Routine blood tests by GP due to impaired fertility showed hyperthyroidism with high TSH.

- At time of clinic appointment, 7/40 after natural conception

- Migrainous headaches in early pregnancy, and vague history of palpitations,

but no clear symptoms of hyperthyroidism

- No personal/family $\mathrm{Hx}$ of thyroid/pituitary problems

- Ex: completely unremarkable

2 days before Christmas

Pre-conception:

free T4 $30.8 \mathrm{pmol} / \mathrm{L}$

free $T 37.5 \mathrm{pmol} / \mathrm{L}$

TSH $5.1 \mathrm{mIU} / \mathrm{L}$

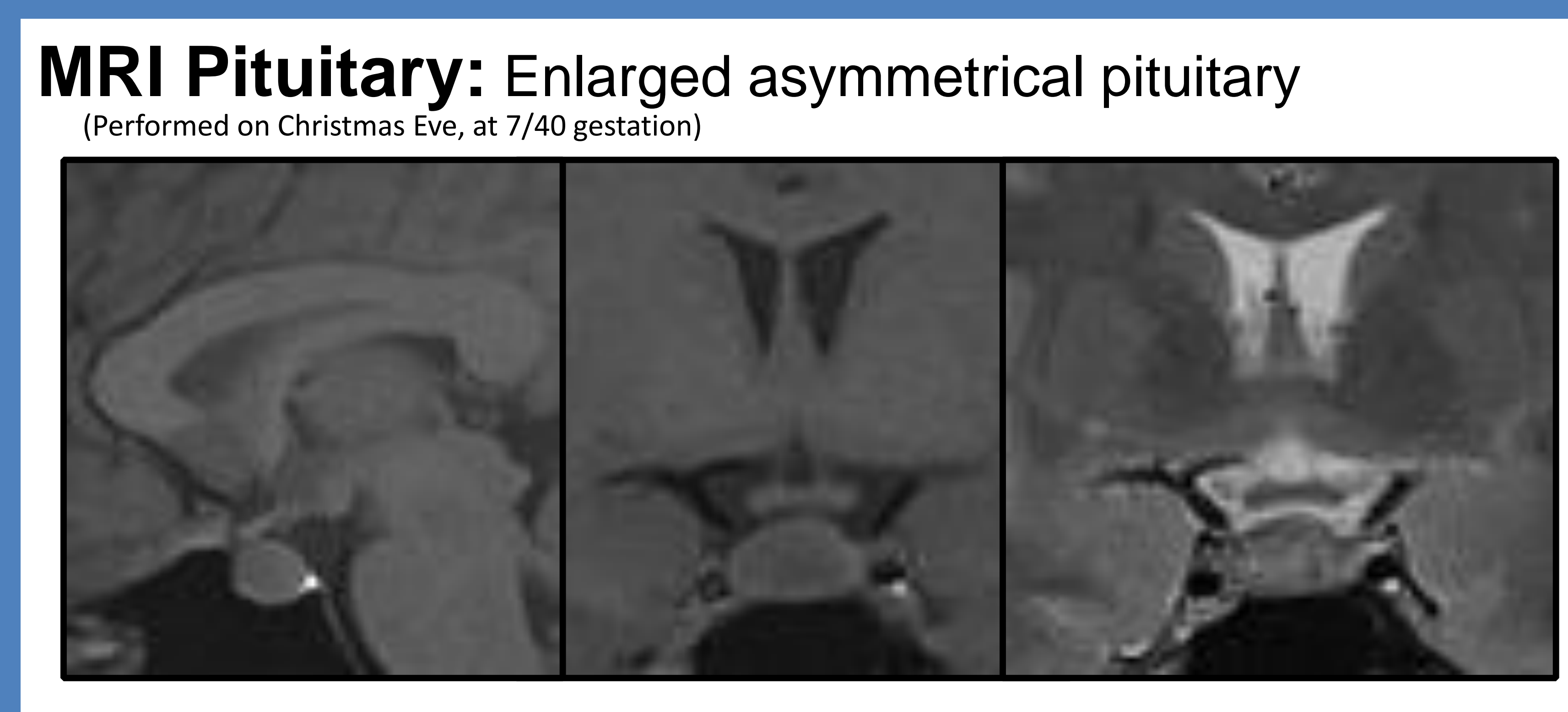

MRI Limitations: Statistically significant increase in pituitary

dimensions at all stages of pregnancy $(p<0.001)$

$36 \%$ increase pituitary volume at $3^{\text {rd }}$ trimester vs.control group ${ }^{1}$

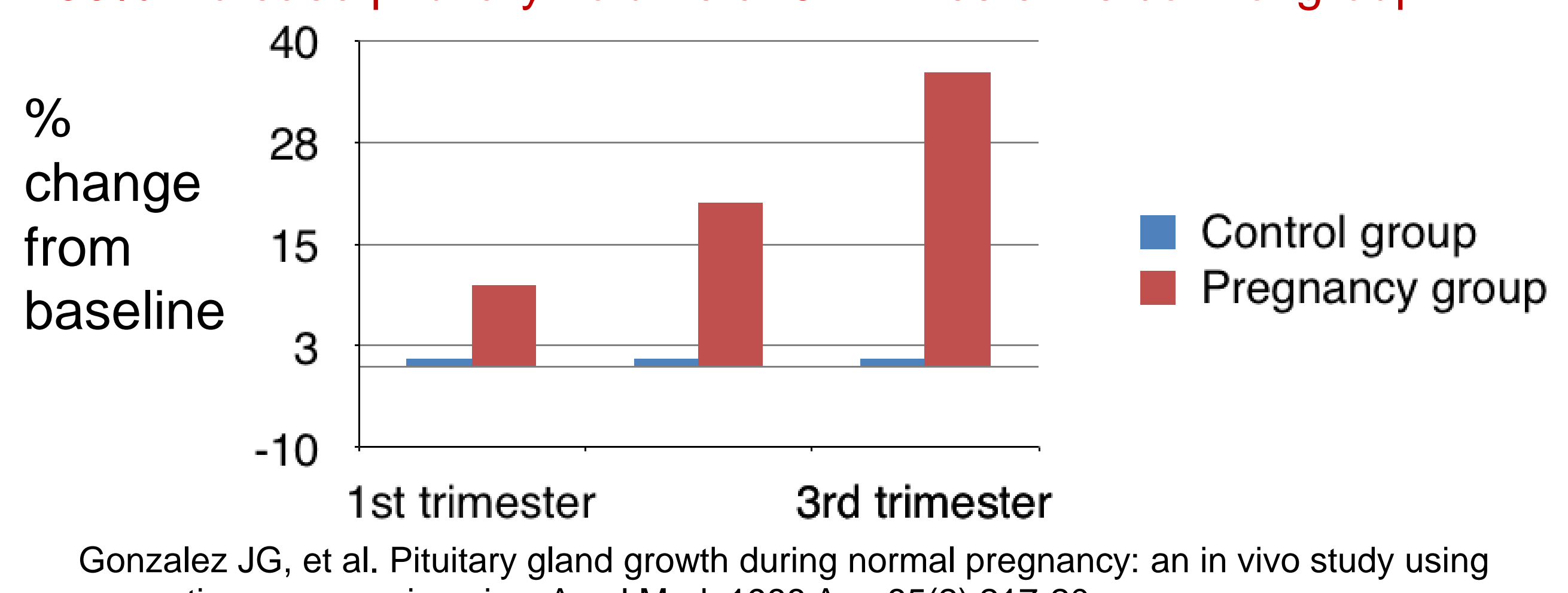

Gonzalez JG, et al. Pitutitary yland grouth during normal pregnancy: an in vivo study using
magnetic resonance imaging. Am J Med. 1988 Aug;:55(2):217-20.

\begin{tabular}{|c|c|c|c|c|c|}
\hline \multicolumn{5}{|c|}{ Biochemistry: } & \multirow{8}{*}{ 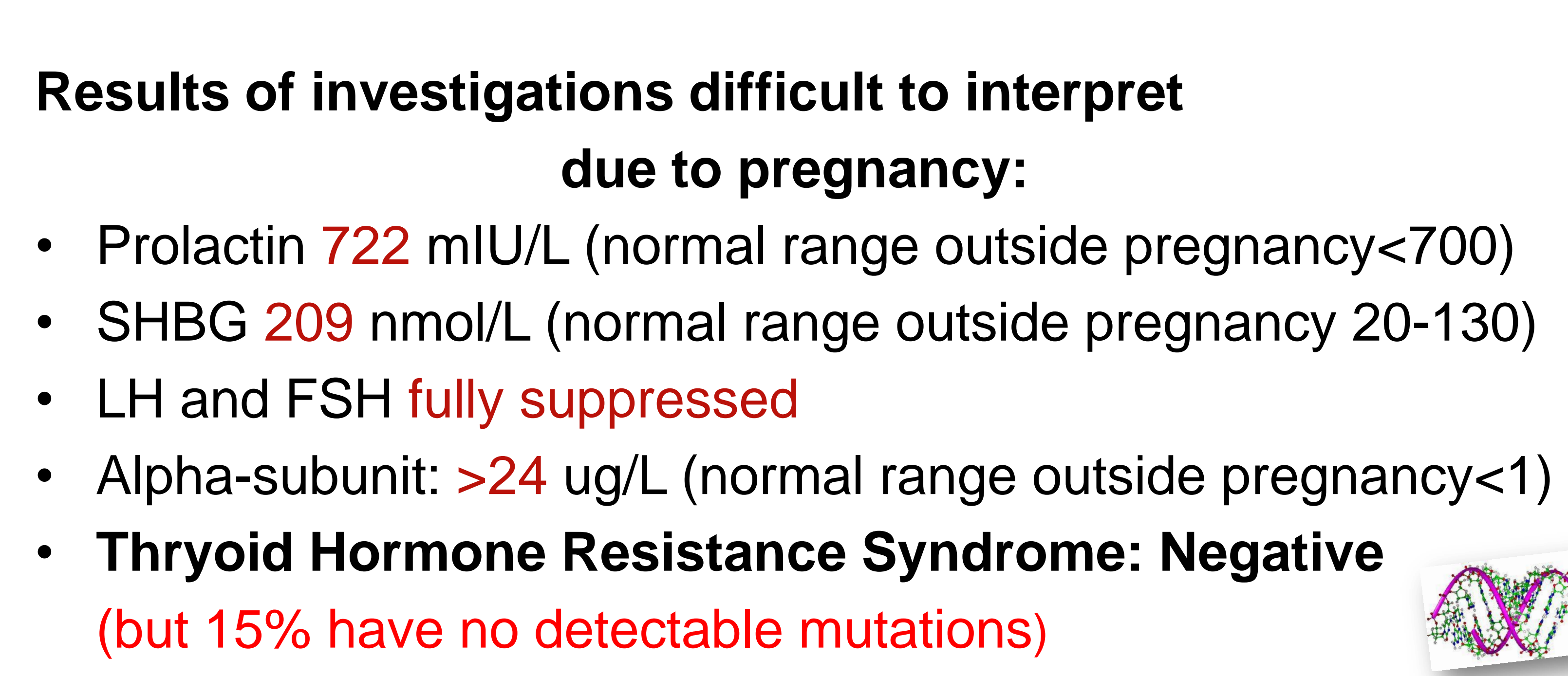 } \\
\hline & 2/11/11 & $23 / 12 / 2011$ & $\begin{array}{c}\text { Ref. Lab } \\
21 / 12 / 2011\end{array}$ & $3 / 01 / 2012$ & \\
\hline TSH & 5.1 & 5.7 & $4.84(0.35-5)$ & 5.3 & \\
\hline T4 & 30.6 & 25.0 & $23.4(9-19.1)$ & 24.2 & \\
\hline T3 & 7.5 & 6.6 & $6.4(2.6-5.7)$ & 6.7 & \\
\hline TRAb & & $<1$ & & & \\
\hline Anti-TPO & & 967 & & & \\
\hline Heterophile Ab & & Negative & & & \\
\hline
\end{tabular}

Biochemistry through pregnancy:

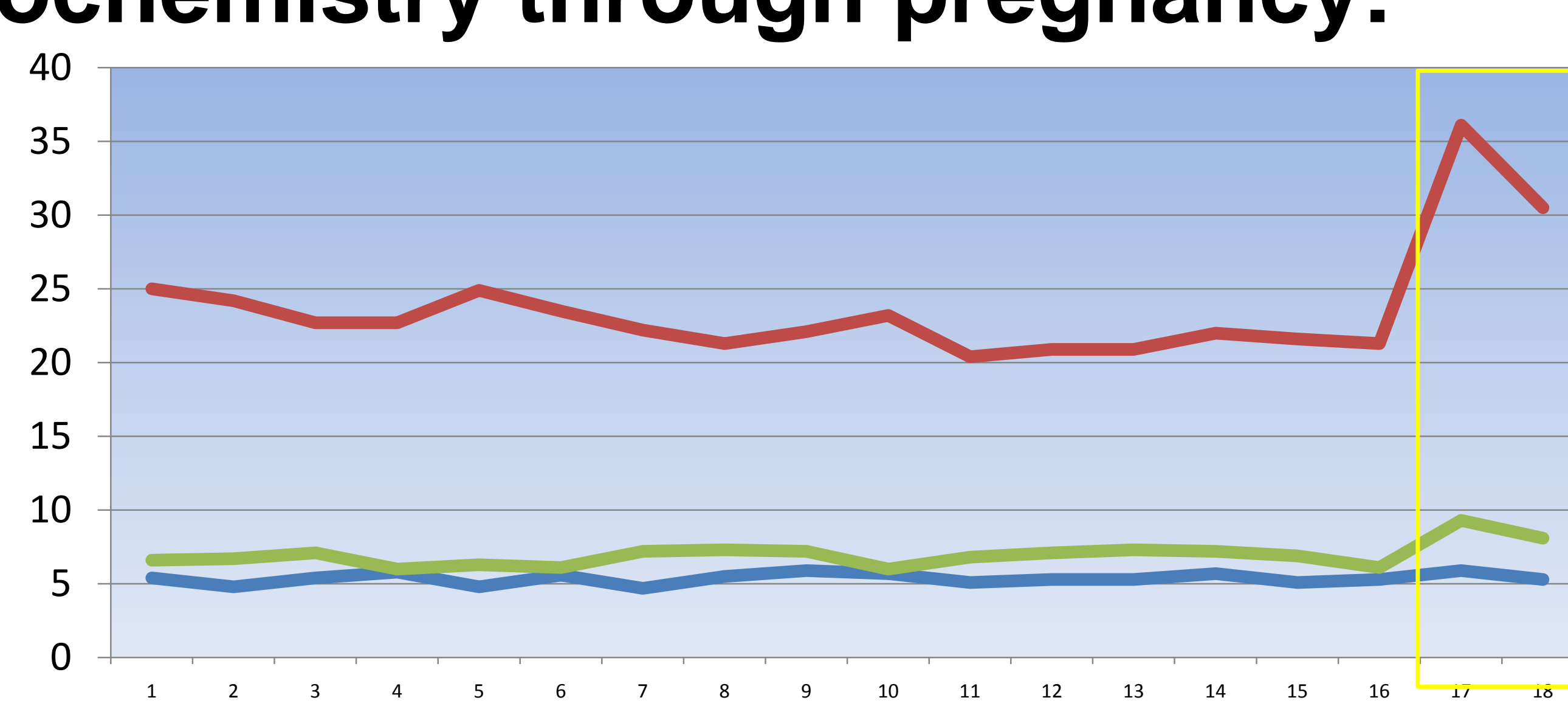

Time

\section{Post partum results}

Thyroid function monitored 2 weekly through pregnancy.

Biochemistry throughout pregnancy remained stable.

A healthy baby boy was delivered after a normal vaginal delivery. His thyroid function tests are all within the normal range

Our patient remained asymptomatic despite an elevation in her free thyroid hormones post partum

\section{Past experience of management:}

TSH secreting Pituitary Adenoma in Pregnancy 3 case reports (all diagnosed preconception). In all cases, pituitary enlargement associated with visual symptoms (3rd trimester). Different management pathways in each report:

1. Continuous subcutaneous octreotide $300 \mathrm{mcg} / \mathrm{day}^{2}$

2. Intermittent subcutaneous octreotide ${ }^{3}$

3. PTU, bromocriptine and decompressive surgery ${ }^{4}$

\section{Thyroid Hormone Resistance and Pregnancy}

- Ideal management pathway remains unclear

- Patients typically asymptomatic unless selective pituitary thyroid hormone resistance present

- Challenges surrounding how to manage the metabolic status of the fetus when it is at odds with maternal metabolic environment.

- Issues regarding frequency of fetal monitoring and intrauterine diagnosis.
Management of TSH Producing Pituitary Tumours Outside of Pregnancy5:

1. Anti-thyroid medications not considered effective:

unless concurrent autoimmune disease

2. Somatostatin analogues: most commonly used.

(cure possibly influenced by somatostatin receptor subtype ${ }^{6}$ ) Biochemical cure (T4/T3 normalisation) in 75\% TSH improvement in $~ 90 \%$ Tumour shrinkage in 33\%

3. Dopamine agonists

less efficacious UNLESS mixed TSH/Prolactin secretion

4. Transphenoidal surgery:

Further surgery required in up to $20 \%$

5. Alternative management:

Thyroid ablation (surgery/radioactive iodine; $n=2$ ),

no changes in pituitary size over 8 and 12 years of follow up

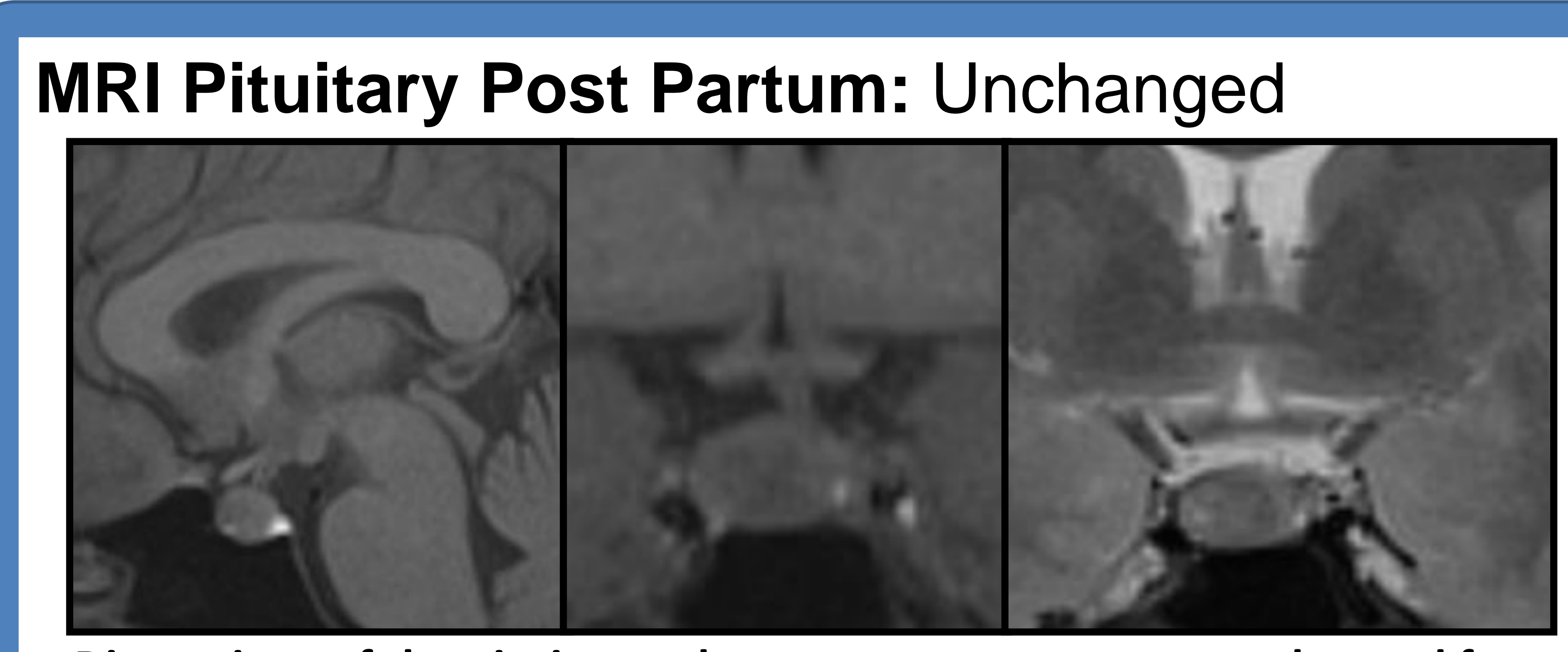

Dimensions of the pituitary adenoma post partum are unchanged from the original MRI performed during the first trimester
Results additional investigations post-partum:

- Prolactin $545 \mathrm{mIU} / \mathrm{L}$ (normal)

- SHBG $120 \mathrm{nmol} / \mathrm{L}$ (normal)

- LH 8.1 and FSH 8.8 (normal)

- Alpha-subunit: 4.95 ug/L (elevated)

Ongoing Management Plan:

Our patient would like to have further pregnancies.

She is scheduled to have transphenoidal pituitary surgery for removal of the adenoma in March 2013. 